\title{
Sağlık Hizmetlerini Vergilerle Finanse Eden Ülkeler Üzerine Ampirik Bir Analiz
}

\author{
DOI: $10.26466 /$ opus.792754
}

*

\author{
Pelin Gençoğlu * - Sevda Kuşkaya** - Nurhan Toğuç*** \\ *Dr., Erciyes Üniversitesi/ KAYHAM, Kayseri/Türkiye \\ E-Posta: pgencoglu@erciyes.edu.tr \\ ORCID: $0000-0003-2985-2875$ \\ ** Öğr. Gör. Dr., Erciyes Üniversitesi/Adalet Meslek Yüksekokulu, Kayseri/Türkiye \\ E-Posta: skuskaya@erciyes.edu.tr \\ ORCID: $0000-0003-4527-5713$ \\ *** Dr. Öğr. Üyesi, İstanbul Esenyurt Üniversitesi/Uluslararası Ticaret, İstanbul/Türkiye \\ E-Posta: nurhantoguc@esenyurt.edu.tr \\ ORCID: $\underline{0000-0002-3891-1163}$ \\ Öz
}

Sağllk, bireylerin kaliteli yaşam sürdürebilmelerini sağlayan temel faktördür. Bireyin sağllkh olabilmesi ve sağhl̆ğtnı koruyabilmesi için düzgün ve etkin işleyen sağlık sisteminin varlı̆̆ına ihtiyaç duyulur. Sağhlk sisteminin etkinliğinde, sağllk hizmetleri maliyetleri ve bu maliyetlere yönelik finansman yöntemleri etkin bir role sahiptir. $B u$ doğrultuda ülkelerin tercih ettikleri finansman yöntemleri önemli bir araştırma konusudur. Sağ lık talebi açısından sağlık hizmetleri finansmanında doğrudan finansman ve dolayl finansman olmak üzere temel iki yöntem bulunmaktadır. Doğrudan finansman yönteminde bireyler, sağllk harcamalarmı doğrudan kendileri öderler. Dolayh finansman yönteminde ise hizmet talep eden ile hizmeti sunan arasinda ödeyici konumda olan üçüncü taraf bulunur. Bu yöntemde kullanulan temel araçlar; genel vergiler, özel vergiler, primler, tüketici katkla$n$ ve bağışlardır. Çalışmada, sağ lık sisteminin vergilerle finansman edildĭ̆gi, dolayl finansman yöntemi dikkate alınmıştır. Bu bağlamda makalede, sağhlk hizmetlerini vergilerle finanse eden 28 ülke analiz edilmiştir. Kümeleme analizinin tercih edildiği çalışmada, ülkelerin sahip oldukları benzer özelliklere bağh olarak dört grupta kümelendikleri belirlenmiştir. Ayn kümede yer alan ülkelerin, vergi gelirlerinin GSYIH payı, kişi başına düşen GSYIH ve insani gelişme indeksi stralamasındaki konumlarma göre birbirlerine yakın konumda yer aldiklarn tespit edilmiştir.

Anahtar Kelimeler: Sağlık hizmetleri, Vergilerle finansman, Kümeleme analiz. 


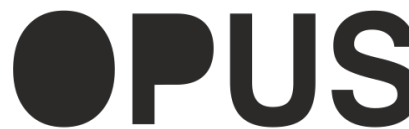

Uluslararası Toplum Araştırmaları Dergisi International Journal of Society Researches
E-ISSN : 2528-9535

YIl Year: 11

Cilt Volume: 18

Sayı Issue :Yönetim ve Organizasyon Özel Sayısı

Temmuz July 2021

Makalenin Gelis Tarihi Received Date: 10/09/2020

Makalenin Kabul Tarihi Accepted Date: 08/06/2021

\title{
An Empiric Analysis on the Countries That Finances Health Services with Taxes
}

\begin{abstract}
Health is the main factor that enables individuals to lead a quality life. In order for the individual to be healthy and to protect his health, there is a need for a properly and effectively functioning health system. Healthcare costs and financing methods for these costs play an important role in the effectiveness of the health system. From this point of view, the financing methods preferred by the countries are an important research subject. In terms of health demand, there have been two main methods of financing health services as direct financing and indirect financing. In the direct financing method, individuals pay their health expenses directly by themselves. On the other side, there is a third party who is the payer between the service requester and the service provider in the indirect financing method. The main instruments used in this method are uniform taxes, specific taxes, premiums, consumer contributions and endowments. In the study, the indirect financing method, which is the health system financed by taxes, has been taken into consideration. In this context, 28 countries that finance their health services with taxes are analyzed in this article. In the analysis in which cluster analysis was preferred, it was determined that countries cluster in four groups depending on their similar characteristics. Countries in the same cluster have been found to be close to each other in terms of their positions in GDP share of the tax revenues, GDP per capita, and human development index.
\end{abstract}

Keywords: Health services, Tax funding, Cluster analysis. 


\section{Giriş}

Bireylerin kaliteli yaşam sürdürebilmeleri için gerekli olan temel faktörlerin başında sağlık gelmektedir. Bireylerin sağlıklı olmaları, o ülkedeki sağlık hizmetleri ile yakından ilişkilidir. Sağlık hizmetleri, insan ve toplum sağllğına zarar veren etkenleri ortadan kaldırılarak toplum sağlığını etkilemesinin önüne geçmek, hastaları tedavi etmek, mevcut fiziksel ve psikolojik durumunda sorun yaşayan kişilerin işe uyumlarını sağlamak için yapılan faaliyetler olarak tanımlanmaktadır. İnsanların ülkelerinde ki mevcut sağlık hizmetlerine erişebilmeleri ise ülkenin sağlık düzeyini göstermektedir.

Ülkelerin sağlık sistemlerinin etkin ve sürdürülebilir bir işleyişe sahip olması, toplumun sağlık düzeyi açısından önemlidir. Bu bağlamda sağlık hizmetleri finansmanı nasıl yapılmadığı da ön plana çıkmaktadır. Bunun temel nedeni ise sürdürülebilir bir sistemin, etkin bir sağlık hizmeti finansman kaynağına sahip olması gerekliliğidir. Sağlık hizmetlerinin artan yüksek maliyete sahip olması farklı finansman kaynakları kullanımını ortaya çıkarmaktadır. Günümüzde küresel boyutta yaşanan COVID-19 salgını da sağlık hizmetleri maliyeti ve finansmanının önemini gösteren önemli bir örnektir.

Sağlık hizmetleri finansman kaynakları sağlık talebi açısında doğrudan ve dolaylı finansman kaynakları olmak üzere ikiye ayrılmaktadır. Zaman içerisinde alternatif finansman kaynakları ortaya çıkmıştır. Bu çalışma, sağlık hizmetlerinde dolaylı finansman yöntemlerinden birisi olan vergilerle finansman yöntemini dikkate almıştır. Analiz yöntemi olarak kümeleme analizi tercih edilmiştir. Kümeleme analizi, grup halindeki verileri benzerliklerine göre sınıflandırmada tercih edilen çok değişkenli istatistik yöntemlerden birisidir. Analiz yardımıyla, sağlık harcamalarını vergilerle finanse eden 28 ülkenin 2017-2018 dönemindeki durumları incelenerek, sahip oldukları benzerlikler neticesinde nasıl gruplandıkları değerlendirilecektir.

Makale beş bölümden oluşmaktadır. Birinci bölümde sağlık hizmetlerinin finansman yöntemleri hakkında bilgi verilmiştir. İkinci bölüm, sağlık hizmetlerinin finansmanına yönelik yapılan birtakım çalışmaları içermektedir. Üçüncü ve dördüncü bölümlerde ise sırasıyla yöntem, veri seti ve analiz sonuçları yer almıştır. Son bölüm sonuç bölümü içermektedir. 


\section{Sağlık Hizmetleri ve Finansman Yöntemleri}

Sağlık hizmetleri, Sağlık Hizmetlerinin Sosyalleştirilmesi Hakkında Kanun'da (1961), insan ve toplum sağllğına zarar veren etkenlerin ortadan kaldırılarak toplum sağlığını etkilemesinin önüne geçmek, hastaları tedavi etmek, mevcut fiziksel ve psikolojik durumunda sorun yaşayan kişilerin işe uyumlarını sağlamak için yapılan faaliyetler olarak tanımlanmaktadır. Dünya Sağlık Örgütü'ne göre sağlık hizmetleri, insan sağlığı için tehdit oluşturan faktörlerin ortadan kaldırılması, mevcut hastalıklara tanı konulması, tespit edilen hastalıkların tedavi edilmesi, bedensel ya da zihinsel yeteneklerin azalması veya tamamen kaybedilmesi durumunda gerekli iyileştirme faaliyetlerini kapsayan tüm tıbbi hizmetlerdir. Sağlık hizmetleri tanımları dikkate alındığında, sağlık hizmetlerinin farklı amaçlara sahip olduğu anlaşılmaktadır. Bu doğrultuda sağlık hizmetleri, koruyucu sağlık hizmetleri, tedavi edici sağlık hizmetleri ve rehabilite edici sağlık hizmetleri olmak üzere üç grupta toplanmaktadır (Kök ve Sayım, 2009, ss.277-278; Batırel, 1993, s.18; Dağll, 2006, s.21). Koruyucu sağlık hizmetleri, hastalık durumunun ortaya çıkmasını engelleyen önleyici hizmetleri ifade etmektedir. Bu tip sağlık hizmetleri, anne-çocuk sağlığı korunması, çevre kirliliğinin önlenmesi, iş yeri çalışma koşullarının iyileştirilmesi gibi birçok hizmeti kapsamaktadır. Tedavi edici sağlık hizmetleri, hasta bireylerin sağlık durumunu iyileştirmek için başvurulan tıbbi hizmetlerdir. Rehabilite edici sağlık hizmetleri ise, kaza ve benzeri sebeplerle bireylerin yaşadıkları psikolojik sorunlar, engelleyici kısıtlılık gibi durumların etkilerini ortadan kaldırmak ya da hafifletmek amacıyla sunulan sağlık hizmetleridir. Ortak hedefi bireye ve topluma fayda sağlamak olan sağlık hizmetlerinin her biri belirli maliyetlere sahiptir. Türlerine göre maliyet farklılıklarına sahip olmalarına karşın sağlık hizmetlerinin tamamından elde edilen fayda, katlanılması gereken maliyetten her zaman yüksek olacaktır (Fanshel ve Bush, 1970, s.1059). Bu duruma bağlı olarak, ortaya çıkan maliyetlerin kim tarafından ve nasıl finanse edileceği soruları ön plana çıkmaktadır.

Sağlık hizmetleri finansmanında sağlık talebi açısından temel iki yöntem vardır. Bunlar, doğrudan finansman ve dolaylı finansmandır. Son yıllarda bu iki yöntem dışından alternatif yöntemler de ortaya çıkmıştır (Yıldırım, 1994, ss.39-42; Aktan ve Işık, 2006, s.5-7). 
- Doğrudan Finansman Yöntemi: Sağlık hizmeti talep eden bireyin, aldığ1 sağlık hizmetinin ücretini doğrudan kendisinin ödediği yöntemdir. Tüketici konumundaki birey piyasa mekanizması işleyişinde olduğu gibi hareket eder.

- Dolayl Finansman Yöntemi: Bu yöntemde hizmet talep eden ile hizmeti sunan arasında ödeyici konumda olan bir üçüncü taraf söz konusudur. Üçüncü taraf sağlık sigortası kapsamında kamu ya da özel sektör olabilmektedir. Dolaylı finansman yönteminde, sağlık sisteminin işleyişinde genel vergiler, özel vergiler, primler, tüketici katkıları ve bağışlar yer almaktadır.

- Alternatif Yöntemler: Maliyet paylaşımı, tüketici katkıları ve gönüllü sağlık kuruluşları tarafından yapılır. Maliyet paylaşımında, sağlık hizmeti talebinde bulunan birey hizmetin maliyetinin bir kısmını yüklenir. Bu durum, sağlık hizmetinin belli aşamaları ya da tamamı için geçerli olabilmektedir. Tüketici katkılarında, sağlık hizmeti tüketiminde bulunan birey doğrudan bir kısım harcamayı cebinden yapmaktadır. Gönüllü sağlık kuruluşlarında ise, vakıflar, dernekler ve hayır kurumları yer almaktadır. Bu tip sağlık kuruluşları verdikleri sağlık hizmeti maliyetini düzenledikleri etkinliklerden elde ettikleri kaynaklarla sağlarlar.

Dolaylı finansman yöntemlerinden biri olan vergilerle finansmanda, sağlık harcamalarının büyük bir kısmı bireyler tarafından ödenen ve bir havuzda biriken vergilerle karşılanmaktadır. Diğer bir ifadeyle, devlet, havuzda biriken vergi gelirleri ile sağlık hizmetlerini finanse eder. Bu finansman yönteminde bireyler vergi ve sağlik hizmeti kullanımı aşamasında belirlenen yasal katkı payı hariç herhangi bir ödemede bulunmazlar. Bütün toplumu kapsayan sistemde, ihtiyaç duyulan hizmete zaman ya da kişi ayrımı yapılmaksızın ulaşılır. Yani, bireyin ödediği vergi miktarı, sağlık hizmeti alma hakkı üzerinde herhangi bir etkiye sahip değildir (Uğurluoğlu ve Özgen 2008, ss.138-139; Tatar, 2011, ss.112-113). Bunun yanı sıra ülkeler arasında devletin sağlık hizmeti finansmanı katkı oranında farklılıklar ortaya çıkabilmektedir. Ülkelerin gelir düzeyi, gelişmişlik seviyesi gibi faktörler bu farklılığın sebepleri arasında yer almaktadır. 


\section{Literatür Özeti}

Literatürde sağlik hizmetlerinin finansmanına yönelik çalışmalar bulunmaktadır. Bu çalışmaların, çoğunluğunda teorik olarak sağlık hizmetlerinin finansman yöntemlerini ele aldıkları görülmektedir.

Liaropoulos (1995) çalışmasında Yunanistan'da sağlık hizmetlerinin finansmanında özel sağlık sigortasının rolünü incelemiştir. Araştırma neticesinde, Yunanistan'da ki özel sağlık sigortasının bu rolü üstlenmekte yetersiz kaldığı sonucuna ulaşmıştır. Özel sağlık sigortasında ki hızlı artış, kamu sektörünün yetersiz finansmanı ve özel sektör için kısıtlayıcı politikalar neticesinde oluştuğunu ifade etmiştir. Ayrıca, özel sektörün büyük ölçüde özel sağlık sigortası tarafından finanse edildiği belirtilmiştir. Yazar, kamu sektörü ile özel sağlık sigortası arasında, halk sağlığı hizmetlerinin sunumunu ve sağllk sisteminin genel teknik, tahsisat ve dinamik verimliliğini artıracak bir iş birliği yapılmasını önermiştir.

Işık (2001)' a göre Dünya' da ve Türkiye'de sağlık hizmetlerinin en iyi şekilde sunulabilmesi için hem kamu hem de özel sektör finansman kaynaklarına ihtiyaç vardır. Sağlık bilincinin artması, gelir seviyesinin yükselmesi, bilimsel gelişmeler ve diğer birçok nedene bağlı olarak artan sağllk harcamalarının karşılanmasında kıt olan kaynaklar tüm finansman yöntemlerinin birlikte uygulanmasını zorunlu kılmaktadır. Araştırmaya göre, özel sağlık sigortası daha çok gelişmiş olan ülkelerde tercih edilen bir finansman yöntemi olmakla beraber gelişmekte olan ülkelerde kısıtlı da olsa uygulanmaktadir.

Liu ve Mills (2002) Çin'de halk sağlığı hizmetlerinin finansman reformlarını incelemişlerdir. Yazarlar, halk sağlığı hizmetlerinin finansmanında hükümetin rolünün azalmasının, sağlık sektörünün genel verimliliğinin düşmesine neden olacağın ifade etmişlerdir. Ayrıca, halk sağlı̆̆ hizmetlerine ilişkin ücretlendirmenin, bu hizmetlere olan talebi azaltabileceğini ve hastalık bulaşma riskini artırabileceğini belirtmişlerdir. Çin ekonomisi için, halk sağlığı hizmetlerinin piyasaya yönelik finansman reformları bir politika seçeneği olarak görülmemelidir. Araştırma neticesinde, Çin Hükümeti'nin halk sağlığı hizmetlerini finanse etmede çok aktif bir rol üstlenmesi gerektiği sonucuna ulaşmışlardır.

Çelikay ve Gümüş (2010) birkaç ülkenin sağlık finansman sistemleri ile Türk sağlık finansman sistemini karşılaştırarak, özel sektörün ya da piyasa 
mekanizması ile fiyatlandırma yolu ile sağlık hizmetinin sunulmasının etkin kaynak tahsisinde başarılı olmadığı sonucuna varmışlardır.

Tatar (2011) çalışmasında, Türkiye'de sağlık hizmetlerinin finansmanında yoğun olarak tercih edilen sosyal sigorta modelini teorik açıdan dikkate almıştır. Araştırmacı, sağlık hizmetlerinin kullanımının artmasında hizmete erişiminde kolaylık, hizmet kullanımını teşvik edilmesi gibi uygulamaların etkili olduğunu ifade etmiştir.

Tekin ve Çelik (2012) politika haritalama yöntemini kullanarak Türkiye'de ki sağlık altyapı yatırımlarında bir finansman yöntemi olarak KamuÖzel Ortaklığı (KÖO) politikasını incelemiştir. Makalenin örneklemini, Türkiye'de sağlık sektöründe altyapı finansman yöntemi olarak KÖO politikası içinde yer alan kamu ve özel sektör temsilcileri ve bu politika ile ilgili diğer kişi ve gruplar oluşturmuştur. Mayıs-Kasım 2009 döneminin dikkate alınd1ğı analiz sonuçlanı, politikanın güçlü şekilde desteklendiğini ve uygulanabilir bir politika olduğunu göstermiştir.

Erumut (2014) mevcut sağlık finansman yöntemleri çerçevesinde bazı ülke uygulamalarını inceleyerek Türkiye için etkin olan sağlık finansman modeli üzerinde çalışmıştır. Çalışmanın sonucunda, Türkiye'de var olan birtakım ekonomik nedenlerle, sağlık prim gelirlerinin sağlık giderlerini karşılama konusunda yetersiz kaldığı sonucuna ulaşılmıştır.

Arık ve İleri (2016) sağlık hizmetlerinde bir geri ödeme yöntemi olarak, Türkiye'de teşhis ilişkili gruplar (TIG) sisteminin etkinliğini inceleyerek, TİG sisteminin sağlık finansmanının sürdürülebilirliğini sağlayabileceğini öngörmüşlerdir.

Gülay (2017) çalışmasında, sağlık sigortacılığı ile Türk ve İngiliz Sağlık finansman sistemlerinin genel yapısını ele alınmıştır. Yazara göre, Türkiye ekonomisi için, vergilere dayalı finansman mekanizması olan Beveridge Sistemi etkin bir yöntem olabilecektir.

Kocataşkın (2019)'a göre Türkiye'de sağlık hizmetlerinin finansmanının önemli bir kolunu oluşturan SGK'nın başlıca gelirini oluşturan primler 1980 'den sonra yetersiz kalmış ve sonrasında da açık vermeye devam etmiştir. İlgili soruna çözüm olarak hazineden, genel vergi gelirlerinden transferler yapılmaya başlanmıştır. Söz konusu transferler, SGK primlerinin karşılaması gereken sağlık harcamalarına yatırıldığı için kamusal yatırımlar ve harcamalardan kısılmıştır. Bu durum, çifte vergilemeye benzer bir duruma sebebiyet vermiştir. 
Zhou vd. (2020) Çin için sağlık bakımı finansmanını incelemişlerdir. İnceleme neticesinde Çin'in sağlık-bakımının performansı 2008-2013 döneminde iyileştiğini, sağlık hizmetlerine fon sağlamak için düşük oranlı katkılar kullanmanın yoksullar için adil olmadığını belirlemişlerdir. Eşit sağlık bakımı finansman dağıtımı elde etmek için alınacak önlemler arasında, sağlık sigortası programları tarafından sunulan uygun paketlerde ki iyileştirmeler ve temel sağlık hizmetlerinin sağlanması gerektiğini belirtmişlerdir.

Bu çalışma, literatürdeki makaleleri inceledikten sonra, sağlık hizmetlerini vergilerle finanse eden ülkelerin durumunu kümeleme analizi ile araştırarak literatüre katkı sağlamayı amaçlamaktadır.

\section{Yöntem-Veri Seti}

Çalışmada, sağlık harcamalarını vergilerle finanse eden ülkeler arasında ki benzerlikleri incelemek amaciyla kümeleme analizi tercih edilmiştir. Kümeleme modeli, birçok araştırmada kullanılan istatistik analiz yöntemlerinden birisidir (Örneğin; Öz vd., 2009; Çelik, 2013; Gençoğlu ve Kuşkaya, 2016; Danacı ve Koçtürk, 2017; Kuşkaya ve Gençoğlu, 2017; Akdamar, 2019 gibi). $\mathrm{Bu}$ modelde bağımlı-bağımsız değişken ayrımı yapılmamaktadır. Bu durum, nasıl gruplandığı yönünde net bir fikre sahip olunamayan değişkenlerin alt grup ayrımlarının yapılabilmesine imkân tanımaktadır (Özdamar, 1999, s.257). Genel olarak analiz yardımıyla, aynı küme içinde yer alan birimler birbirine yakın, oluşan bu kümeler ise birbirine uzak şekilde konumlanmaktadır (Nakip, 2006, ss.437-439 ve Akın ve Eren, 2012, s.176).

Kümeleme analizi yöntemleri arasından, hiyerarşik kümeleme tercih edilmiştir. Bunun temel sebebi ise, küme sayısı ile ilgili net ön bilginin bulunmamasıdır (Özdamar, 1999, s.271). Hiyerarşik kümeleme yöntemleri arasından ise, yaygın olarak kullanılan Ward yöntemi tercih edilmiştir. Analizde yığışım tablosu ve ağaç grafiği yardımıyla uygun küme sayısı belirlenecektir.

Analizde yer alan ülkeler belirlenirken, Atabey (2012)'in çalışmasında ki sınıflandırma dikkate alınmıştır. Türkiye'nin de dahil edildiği sağlık harcamalarını vergilerle finanse eden 28 ülke Tablo 1'de yer almaktadır. 
Tablo 1. Analize Dahil Edilen Ülkeler

\begin{tabular}{llllll}
\hline Brezilya & Danimarka & İrlanda & Norveç & Rusya & İsveç \\
Bulgaristan & Finlandiya & İtalya & Filipinler & Suudi Arabistan İngiltere \\
Kanada & Yunanistan & Kazakistan & Polonya & Sierra Leone & Venezuela \\
Çin & İzlanda & Litvanya & Portekiz & İspanya & \\
Küba & İran & Yeni Zelanda & Romanya & Sri Lanka & \\
\hline
\end{tabular}

Analizde kullanılan değişkenler; World Bank Health Data'dan temin edilmiştir. Verilerin ulaşılabilirliği göz önünde bulundurularak çeşitli sosyoekonomik göstergeler analize dahil edilmiştir. İlgili göstergelere ait veriler, 2017-2018 yılına aittir. Analizde yer verilen değişkenlerin tamamı, Tablo 2'de yer almaktadır.

Tablo 2. Analizde Kullanılan Değişkenler

\begin{tabular}{ll}
\hline Değişken Adı & Birim \\
\hline Yaşlı bağımlılık oranı & $\%$ \\
Genç bağımlılık oranı & $\%$ \\
Kaba doğum oranı & Bin kişi başına \\
Cari sağlık harcamalarının GSYİH payı & $\%$ \\
Kişi başına sağlık harcamaları (sgp) & $\$$ \\
Kamu sağlık harcamalarının GSYİH payı & $\%$ \\
Kamu sağlık harcamalarının toplam kamu harcamalarındaki & $\%$ \\
payı & \\
Doğurganlık oranı & Kadın başına \\
Doğumda yaşam beklentisi & Yıl \\
Ölüm oranı (beş yaş altı) & Bin bebek başına \\
\hline
\end{tabular}

\section{Analiz Bulguları}

Ward yönteminin kullanıldığı çalışmada küme sayısını belirlemek için sırasıyla yığışım tablosu ve ağaç grafiği kullanılmıştır. Yığışım tablosu, Tablo 3 'te yer almaktadır. Yığışım tablosunda yer alan katsayılar arasında ki fark yardımıyla küme sayısı tahmin edilmektedir. Katsayılar arasındaki farkın belirgin bir şekilde arttı̆̆ aşama dikkate alınarak küme sayısı belirlenmektedir. 
Tablo 3.Yığıı̧ım Tablosu (Agglomeration Schedule)

\begin{tabular}{|c|c|c|c|c|c|c|}
\hline \multirow[t]{2}{*}{ Aşama } & \multicolumn{2}{|c|}{ Birleştirilmiş Küme } & \multirow[t]{2}{*}{ Katsayılar } & \multicolumn{2}{|c|}{$\begin{array}{l}\text { Kümenin İlk Görüldüğü } \\
\text { Aşama }\end{array}$} & \multirow{2}{*}{$\begin{array}{l}\text { Sonraki } \\
\text { Aşama }\end{array}$} \\
\hline & Küme 1 & Küme 2 & & Küme 1 & Küme 2 & \\
\hline 1 & 12 & 20 & 0,182 & 0 & 0 & 6 \\
\hline 2 & 17 & 19 & 0,424 & 0 & 0 & 9 \\
\hline 3 & 4 & 11 & 0,673 & 0 & 0 & 7 \\
\hline 4 & 7 & 27 & 0,941 & 0 & 0 & 10 \\
\hline 5 & 21 & 22 & 1,236 & 0 & 0 & 13 \\
\hline 6 & 10 & 12 & 1,615 & 0 & 1 & 8 \\
\hline 7 & 4 & 18 & 2,086 & 3 & 0 & 20 \\
\hline 8 & 6 & 10 & 2,581 & 0 & 6 & 14 \\
\hline 9 & 2 & 17 & 3,105 & 0 & 2 & 13 \\
\hline 10 & 7 & 14 & 3,659 & 4 & 0 & 16 \\
\hline 11 & 9 & 13 & 4,439 & 0 & 0 & 16 \\
\hline 12 & 5 & 15 & 5,367 & 0 & 0 & 18 \\
\hline 13 & 2 & 21 & 6,391 & 9 & 5 & 23 \\
\hline 14 & 6 & 28 & 7,583 & 8 & 0 & 23 \\
\hline 15 & 3 & 24 & 9,143 & 0 & 0 & 19 \\
\hline 16 & 7 & 9 & 10,951 & 10 & 11 & 20 \\
\hline 17 & 1 & 25 & 13,248 & 0 & 0 & 19 \\
\hline 18 & 5 & 26 & 15,813 & 12 & 0 & 24 \\
\hline 19 & 1 & 3 & 18,763 & 17 & 15 & 22 \\
\hline 20 & 4 & 7 & 21,953 & 7 & 16 & 21 \\
\hline 21 & 4 & 16 & 26,170 & 20 & 0 & 25 \\
\hline 22 & 1 & 8 & 33,849 & 19 & 0 & 24 \\
\hline 23 & 2 & 6 & 43,731 & 13 & 14 & 25 \\
\hline 24 & 1 & 5 & 58,180 & 22 & 18 & 26 \\
\hline 25 & 2 & 4 & 85,350 & 23 & 21 & 27 \\
\hline 26 & 1 & 23 & 149,667 & 24 & 0 & 27 \\
\hline 27 & 1 & 2 & 270,000 & 26 & 25 & 0 \\
\hline
\end{tabular}

Tablo 3'te ki katsayılar incelendiğinde 24. aşamada önemli bir artışın olduğu gözlemlenmektedir. Bu aşama dahil geri kalan aşamalarda da artışların devam ettiği gözlemlenmiştir. Bu durum, ülkelerin dört grupta kümelendiklerini işaret etmektedir. Yığışım tablosunun ardından Şekil 1'de yer alan ağaç grafiği dört kümenin mevcudiyetini desteklemektedir. 


\section{Birleştirilmiş}

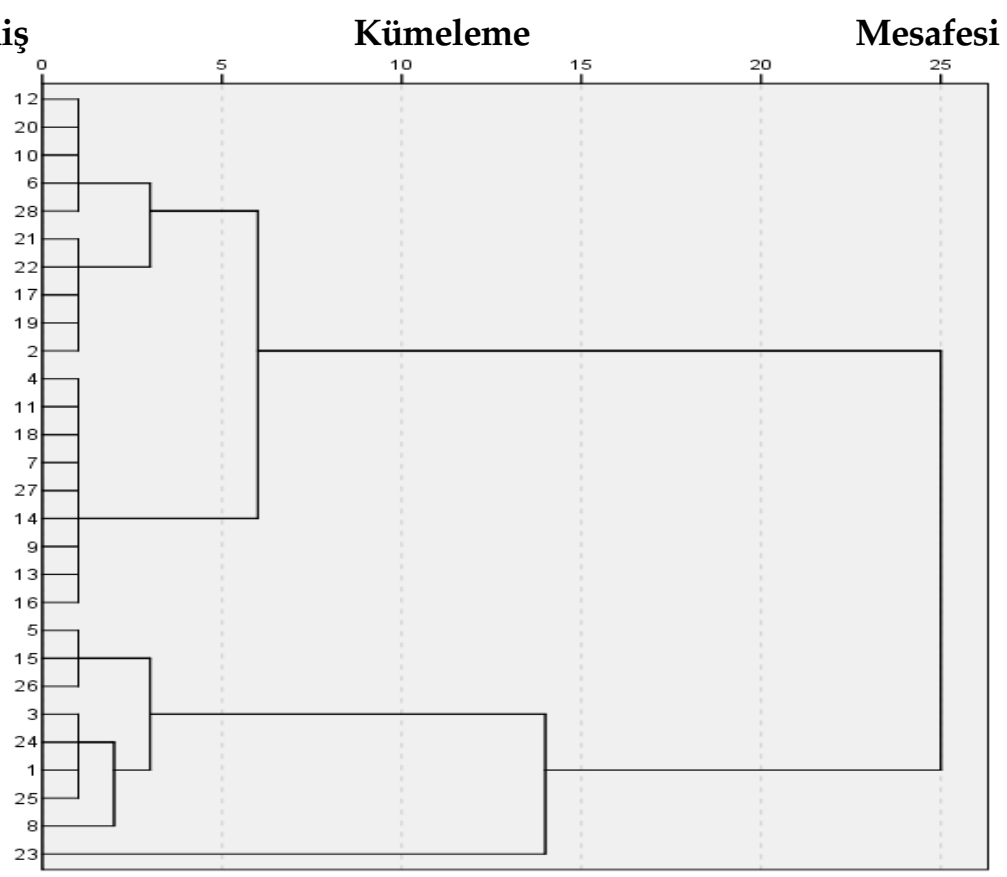

Şekil 1. Ward Yöntemiyle Oluşturulan Ăğaç Grafiği (Dendrogram)

Yığışım tablosu ve ağaç grafiği incelendiğinde, oluşan dört küme ve bu kümelerde yer alan ülkeler Tablo 4'te yer almaktadır.

Tablo 4. Kümeleme Tablosu

\begin{tabular}{ll}
\hline Küme Numarası & Kümede Yer Alan Ülkeler \\
\hline \multirow{3}{*}{ Birinci Küme } & İtalya, Portekiz, İspanya, Finlandiya, Yunanistan, Roman- \\
& ya, Rusça, Litvanya, Polonya, Bulgaristan \\
& Danimarka, İsveç, Norveç, İngiltere, Yeni Zelanda, Kanada, \\
İkinci Küme & İzlanda, İlanda, Küba \\
& Filipinler, Kazakistan, Venezuela, Çin, Sri Lanka, Brezilya, \\
Üçüncü Küme & Suudi Arabistan, İran \\
Dördüncü Küme & Sierra Leone \\
\hline
\end{tabular}

\section{Sonuç ve Değerlendirmeler}

Bireylerin sağlık düzeylerini korumalarını sağlayan sağlık hizmetlerinin amacl; insan ve toplum sağlığına zarar veren etkenleri ortadan kaldırılarak bunların toplum sağlığını etkilemesini engellemek, hastaları tedavi etmek, 
mevcut fiziksel ve psikolojik durumunda sorun yaşayan kişilerin işe uyumlarını sağlamaktır. Böylece hem bireylerin hem de toplumun sağlık düzeyi açısından mevcut ve muhtemel sorunların önüne geçilebilmektedir.

Sağlık düzeyi üzerinde etkili olan sağlık hizmetlerinin arzı ve talebi ülkelerin sağlık sistemleri ile doğrudan ilintilidir. Sağlık sistemlerinin temel belirleyicilerinden birisi, sağlık hizmetleri finansman yöntemidir. Sağlık hizmetleri talebi açısından finansman yöntemleri; doğrudan ve dolaylı finansman yöntemleri olarak ikiye ayrılmaktadır. Vergilerle finansman ise dolaylı finansman yöntemleri arasında yer almaktadır. Mevcut çalışmada vergilerle finansman yöntemi dikkate alınmıştır. Bu finansman yöntemini tercih eden 28 ülkenin 2017-2018 döneminde ki benzerliklerine bağlı olarak durumları kümeleme analizi yardımıyla incelenmiştir.

Kümeleme analizi sonucu belirlenen ülke grupları, kişi başına GSYIH, insani kalkınma endeksi sıralaması ve toplam vergi gelirlerinin GSYIH payı kriterleri dikkate alınarak yorumlandığında (World Bank, 2020; UNDP, 2020);

- İkinci kümede yer alan ülkelerin insanı kalkınma indeksi sıralamasında yer alan ilk on beş ülke arasında yer aldıkları görülmektedir. Kişi başına düşen GSYİH bakımından analize dahil edilen ülkeler arasında en yüksek gelire sahip olanların ayn kümede bulunduğu anlaşılmaktadır. İkinci kümede yer alan ülkelerin kişi başına düşen GSYİH ortalaması \$49979'dır. Vergi gelirlerinin GSYİH'ya oranına bakıldığında ise, küme ortalamasının \%24 olduğu anlaşılmaktadır.

- Birinci kümede yer alan ülkelerin, insani gelişme indeksi sıralamasında 15-55. sıra arasında yer aldıkları görülmektedir. Kişi başına GSYİH ortalaması \$29499, vergi gelirlerinin GSYİH payı ise $\% 18,6^{\prime}$ dır.

- Üçüncü ve dördüncü kümede yer alan ülkelerin belirtilen değişkenlere bağlı olarak en düşük değerlere sahip olduğu gözlenmektedir. Üçüncü kümenin kişi başına GSYİH ortalaması \$20041, vergi gelirlerinin GSYİH payı ise \%9,9'dur. Dördüncü kümede yer alan Sierra Leone'nin kişi başına GSYİH'sı \$1425, vergi gelirlerinin GSYİH payı ise $\% 8,5^{\prime}$ tir.

Genel olarak sonuçlar dikkate alındığında, ülkelerin büyük bir kısmında vergi gelirlerinin GSYİH'ye oranının \%20 ve üzerinde olduğu görülmektedir. Bu ülkelerin belirgin bir şekilde aynı kümelerde (birinci ve ikinci küme) 
yer aldığı gözlemlenmektedir. Dikkate alınan kişi başına GSYİH ve HDI sıralaması bu durumu destekler niteliktedir. Bu durum, yüksek gelişmişlik seviyesi ve gelir düzeyine sahip ülkelerin vergilerle finansman yöntemine daha yakın oldukları işaret etmektedir. Ülkelere ait verilen erişilebilirliğinin sağlanması, örneklemin genişlemesine imkân tanıyacaktır. Böylece yapılacak çalışmalarda daha net sonuçlar alınabilecektir. Sağlık harcamaları finansmanı açısından, vergiler dışındaki diğer dolaylı finansman yöntemleri (primler, tüketici katkıları ve bağışlar vb.) de dikkate alınarak bu çalışmanın bulgularını genişletilmesi gelecekteki çalışmalar için araştırma konusu olarak önerilmektedir. 


\title{
EXTENDED ABSTRACT
}

\section{An Empiric Analysis on the Countries That Finances Health Services with Taxes}

*

\author{
Pelin Gençoğlu- Sevda Kuşkaya- Nurhan Toğuç \\ Erciyes University- Istanbul Esenyurt University
}

Health is one of the basic factors necessary for individuals to lead a quality life. The health of individuals is closely related to the health services in the country. Health services are defined as activities carried out to eliminate the factors that harm human and public health, to prevent them from affecting public health, to treat patients, and to ensure the adaptation of people who have problems in their current physical and psychological conditions. The ability of people to access the available health services in their country shows the health level of the country. It is also important for the health level of the society that the health systems of the countries have an effective and sustainable functioning. In this context, how health services are financed comes to the fore. The main reason for this is that a sustainable system must have an effective health care financing source. The increasing high cost of health services reveals the use of different financing sources.

In terms of health demand, there have been two main methods of financing health services as direct financing and indirect financing. In the direct financing method, individuals pay their health expenses directly by themselves. On the other side, there is a third party who is the payer between the service requester and the service provider in the indirect financing method. The main instruments used in this method are uniform taxes, specific taxes, premiums, consumer contributions and endowments. In recent years, alternative methods have emerged apart from these two methods. In alternative methods, the cost of health care is shared and undertaken by the individuals requesting health care and voluntary health organizations.

In this paper, the indirect financing method, which is the health system financed by taxes, has been taken into consideration. Most of the health expenditures are covered by taxes paid and that accumulated in a 
pool by individuals in this tax financing method. In other words, the government finances health services with the tax revenues accumulated in the pool. In this method, individuals do not make any payments other than taxes and the legal contribution determined during the use of health services. In this system, which covers the whole society, the needed service is reached without discrimination of time or person. That is, the amount of tax an individual pays does not have any effect on his or her entitlement to health care. In addition, there might be differences in the contribution rate of the state's health care financing between countries. These differences might be caused by various factors such as the income level of the countries and the level of development.

Cluster analysis was preferred as the analysis method. This analysis is one of the multivariate statistical methods preferred in classifying grouped data according to their similarity. Among the clustering analysis methods, hierarchical clustering was preferred. The main reason for this is the lack of clear preliminary information about the number of clusters. Among this analysis, the widely preferred Ward method was used. With the help of the analysis, the situation of 28 countries that finance their health expenditures with taxes in the period of 2017-2018 was examined and how they were grouped as a result of their similarities was evaluated.

When the country groups determined as a result of the clustering are interpreted by taking into account the GDP per capita, the ranking of the human development index and the share of total tax revenues in GDP, it is seen that,

- the countries in the first cluster are among the 15-55 in the ranking of the human development index. The average GDP per capita is $\$ 29499$, and the share of tax revenues in GDP is $18.6 \%$.

- the countries in the second cluster are among the first fifteen countries in the human development index ranking. When GDP per capita is taken into account, it is understood that among the countries included in the analysis, those with the highest income are in the same cluster. The GDP per capita of the countries in the second cluster is average $\$ 49979$ and the ratio of tax revenues to GDP is average $24 \%$. 
- the countries in the third and fourth clusters have the lowest values depending on the variables mentioned.

- In general, when the results are taken into account, it can be seen that the ratio of tax revenues to GDP is $20 \%$ and above in most of the countries. It can be also observed that these countries are clearly in the same clusters (first and second clusters). GDP per capita and HDI rankings also support this situation. In this case, it indicates that countries with a high level of development and income are closer to the method of financing with taxes. Ensuring the accessibility of country data will allow the sample to expand. Thus, clearer results can be obtained in further studies. Expanding the findings of this study by considering other indirect financing methods other than taxes is suggested as a research topic for future works.

\section{Kaynakça/References}

Akdamar, E. (2019). OECD ülkelerinin bazı iş gücü piyasası göstergeleri kullanılarak kümeleme analizi ve çok boyutlu ölçekleme analizi ile irdelenmesi. Akademik Araştırmalar ve Çalı̧̧malar Dergisi (AKAD), 11(20), 50-65.

Akın, H. B. ve Ö. Eren. (2012). OECD ülkelerinin eğitim göstergelerinin kümeleme analizi ve çok boyutlu ölçekleme analizi ile karşılaştırmalı analizi. Öneri Dergisi, 10(37),175-181.

Aktan, C. Can ve A. K. Işık. (2006). Sağlık hizmetlerinin finansmanı ve alternatif yöntemler. 15 Ocak 2016 tarihinde http://www.canaktan.org/ekonomi/saglik-degisim-caginda/pdfaktan/finansman-alternatif.pdf, adresinden erişildi.

Arık, Ö. ve İleri, Y.Y. (2016). Sağlık Hizmetlerinin finansmanında Türkiye' de yeni yaklaşım; Teşhis ilişkili gruplar (TİG). SDÜ Sağlık Bilimleri Enstitüsü Dergisi, 7, 45-50.

Batırel, Ö. F. (1993). Sağlık hizmetleri üretimi ve finansmanı konusunda yeni yaklaşımlar. İstanbul Üniversitesi Elektronik Dergisi, 34, 12 Ocak 2012 tarihinde http://www.iudergi.com/tr/indexiphp/iktisatmaliye/aerticle/view/file/14021/13231, adresinden erişildi. 
Çelik, Ş. (2013). Kümeleme analizi ile sağlık göstergelerine göre Türkiye'deki illerin sınıflandırılması. Doğuş Üniversitesi Dergisi, 14(2), 175-194.

Çelikay, F. ve Gümüş, E. (2010). Türkiye'de sağlık hizmetleri ve finansmanı. Eskişehir Osmangazi Üniversitesi Sosyal Bilimler Dergisi, 11(1), 177-216.

Dağlı, H. G. (2006). Türkiye' de sağlık sektörünün yapısı. Yayınlanmamış Yüksek Lisans Tezi. Ankara: Ankara Üniversitesi Sosyal Bilimler Enstitüsü.

Danac1, T. ve Koçtürk, O.M. (2017). Türkiye serbest bölgelerinin kümeleme analizi ile karşılaştırılması. Manisa Celal Bayar Üniversitesi Sosyal Bilimler Dergisi, 15(4), 351 - 370.

Ertürk Atabey, S. (2012). Sağlık sitemleri ve sağlık politikası. Ankara: Gazi Kitabevi

Erumut, M. (2014). Türkiye için alternatif sağllk finansman önerisi: İki sütunlu sistem. Sosyal Güvence Dergisi, 5, 93-126.

Fanshel, S. and J. W. Bush. (1969). A health-status index and its application to health-services outcomes. Operations Research, 18(6), 1021-1066.

Gençoğlu, P. ve Kuşkaya, S. (2016). Küresel cinsiyet uçurumu (Global gender gap) açısından Avrupa ve Orta Asya ülkelerinin değerlendirilmesi: İstatistiksel bir analiz. Uluslararası Sosyal Araştırmalar Dergisi, 9, 696-705.

Gülay, A. (2017). Türkiye'de sağlık sisteminin finansmanı ve İngiltere ile karşılaştırması. Marmara Sosyal Araştırmalar Dergisi, 12, 17-37.

Işık, H. (2001). Sağlık hizmetleri; Finansmanı, ülke örnekleri ve çözüm önerileri. Yayımlanmamış Yüksek Lisans Tezi. Anadolu Üniversitesi Sosyal Bilimler Enstitüsü, Eskişehir.

Kocataşkın, E. (2019). Türkiye'de Sağlı finansman sisteminde genel vergilerin yeri ve önemi. Akademi Sosyal Bilimler Dergisi, 6(17), 270-279.

Kök, M. ve F. Sayım. (2009). Sağlık hizmetlerinde yerel yönetim yatırımları. Uluslararası Sağlıkta Performans ve Kalite Kongresi, 19-21 Mart 2009, Antalya. Bildiriler, Cilt 3, TC Sağlık Bakanlığı, Ankara 2009, 114.

Kuşkaya, S. ve Gençoğlu, P. (2017). OECD Ülkelerinin 1995-2015 yılları itibariyle sera gazı salınımları açısından karşılaştırılması: İstatistiksel bir analiz. International Journal of Disciplines Economics \& Administrative Sciences Studies, 3, 177-188.

Liaropoulos, L.L. (1995). Health services financing in greece: A role for private health insurance. Health Policy, 34, 53-62. 
Liu, X. and Mills, A. (2002). Financing reforms of public health services in China: Lessons for other nations. Social Science \& Medicine, 54, 16911698.

Nakip, M. (2006). Pazarlama araştırmaları teknikler ve (SPSS destekli) uygulamalar. Ankara: Seçkin Yayıncilık.

Öz, B., Taban, S. ve Kar, M. (2009). Kümeleme analizi ile Türkiye ve AB Ülkelerinin beşerî sermaye göstergeleri açısından karşılaştırılması. Eskişehir Osmangazi Üniversitesi Sosyal Bilimler Dergisi, 10(1), 1-29.

Özdamarlar, K. (1999). Paket programlar ile istatistiksel veri analizi-2 (Çok değişkenli analiz) SPSS-Minitab. İkinci Bask1, Eskişehir: Kaan Kitabevi.

Tatar, M. (2011). Sağlık hizmetlerinin finansman modelleri: Sosyal sağlık sigortasının Türkiye'de gelişimi. Sosyal Güvenlik Dergisi, 1(1), 103133.

Tekin, P.Ş. ve Çelik, Y. (2012). Türkiye'de sağlık sektöründe bir finansman yöntemi olarak kamu-özel ortaklığ politikasının politika haritalama yöntemi ile analiz edilmesi. Ankara Sağglık Bilimleri Dergisi, 1(3), 81-98.

Uğurluoğlu, E. ve H. Özgen. (2008). Sağlık hizmeti finansmanı ve hakkaniyet. Hacettepe Sağllk İdaresi Dergisi, 11(2), 133-160.

UNDP. (2020). Human Development Data (1990-2018), 10 Haziran 2020 tarihinde http://hdr.undp.org/en/data adresinden erişildi.

World Bank. (2020). Health Nutrition and Population Statistics, 10 Haziran 2020 tarihinde https://databank.worldbank.org/source/healthnutrition-and-population-statistics adresinden erişildi.

Yıldırım, S. (1994). Sağlık hizmetlerinde harcama ve maliyet analizi. (Uzmanlık Tezi) . Devlet Planlama Teşkilatı, Ankara: Y.no.2350

Zhou, G., Chen, R. and Chen, M. (2020). Equity in health-care financing in china during the progression toward universal health coverage. China Economic Review, 61, 101427.

\section{Kaynakça Bilgisi / Citation Information}

Gençoğlu, P., Kuşkaya, S., ve Toğuç, N. (2021). Sağlık hizmetlerini vergilerle finanse eden ülkeler üzerine ampirik bir analiz. OPUSUluslararası Toplum Araştırmaları Dergisi, 18(Yönetim ve Organizasyon Özel Sayıs1), 1596-1613. DOI:10.26466/opus.792754. 
Sağlık Hizmetlerini Vergilerle Finanse Eden Ülkeler Üzerine Ampirik Bir Analiz 